University of Windsor

Scholarship at UWindsor

\title{
End-of-Life Preparations among Lesbian, Gay, Bisexual, and Transgender People: Integrative Review of Prevalent Behaviors
}

\author{
Luisa Kcomt \\ University of Windsor \\ Kevin M. Gorey \\ University of Windsor
}

Follow this and additional works at: https://scholar.uwindsor.ca/socialworkpub

Part of the Health Policy Commons, Health Services Research Commons, Medical Education

Commons, Palliative Care Commons, Primary Care Commons, Social Welfare Commons, and the Social

Work Commons

\section{Recommended Citation}

Kcomt, Luisa and Gorey, Kevin M.. (2017). End-of-Life Preparations among Lesbian, Gay, Bisexual, and Transgender People: Integrative Review of Prevalent Behaviors. Journal of Social Work in End-of-Life \& Palliative Care, 13 (4), 284-301.

https://scholar.uwindsor.ca/socialworkpub/57

This Article is brought to you for free and open access by the School of Social Work at Scholarship at UWindsor. It has been accepted for inclusion in Social Work Publications by an authorized administrator of Scholarship at UWindsor. For more information, please contact scholarship@uwindsor.ca. 


\title{
End-of-Life Preparations among Lesbian, Gay, Bisexual, and Transgender People: Integrative Review of Prevalent Behaviors
}

\author{
Luisa Kcomt \& Kevin M. Gorey
}

To cite this article: Luisa Kcomt \& Kevin M. Gorey (2017) End-of-Life Preparations among Lesbian, Gay, Bisexual, and Transgender People: Integrative Review of Prevalent Behaviors, Journal of Social Work in End-of-Life \& Palliative Care, 13:4, 284-301, DOI: 10.1080/15524256.2017.1387214

To link to this article: https://doi.org/10.1080/15524256.2017.1387214

曲 Published online: 18 Dec 2017.

Submit your article to this journal $\llbracket$

Q View related articles $\sqsubset$

View Crossmark data ¿ 


\title{
End-of-Life Preparations among Lesbian, Gay, Bisexual, and Transgender People: Integrative Review of Prevalent Behaviors
}

\author{
Luisa Kcomt (D) and Kevin M. Gorey \\ School of Social Work, University of Windsor, Windsor, Ontario, Canada
}

\begin{abstract}
Proactively making end-of-life (EOL) preparations is important to ensure high quality EOL care. Critical to preparation is the discussion of preferences with one's primary health care providers. Lesbian, gay, bisexual, and transgender (LGBT) people often experience discrimination from health care providers that will detrimentally affect their ability to communicate their care preferences. Structural barriers, such as those based on sexual orientation and gender identity, may impede timely and quality care when one is most in need. The aim of this study was to examine the prevalence of EOL preparatory behaviors among LGBT people, with particular focus on transgender individuals. Eight survey instruments with 30 prevalence estimates found in the literature were analyzed. EOL discussions between LGBT people and their primary health care providers were rare (10\%). Transgender people were found to be even less prepared for EOL; they were $50-70 \%$ less likely than their LGB counterparts to have a will, a living will or to have appointed a healthcare proxy. A need exists for future mixed-methods research focused on LGBT populations accompanied by the cultural sensitivity needed to ensure their wishes are honored at the EOL.
\end{abstract}

\section{KEYWORDS}

Advance care planning; end-of-life preparation; LGBT; living will; transgender people

Most Americans avoid conversations about death and dying and discussing preferences about the end-of-life (EOL) is uncomfortable for them and their health care providers. This discomfort is a barrier to effective communication, the cornerstone of high quality medical care. Indeed, the Institute of Medicine has recognized this as a significant gap in the preparation of medical and allied health professionals who care for and comfort those with advanced illness (2014, p. 4). Population aging in concert with the increased visibility of lesbian, gay, bisexual, and transgender (LGBT) people has stimulated interest in advancing understanding about the provision of high quality EOL care generally and for members of the LGBT community specifically. Sadly, and unacceptably, LGBT people still experience pervasive discrimination in health care (Buckey \& Browning, 2013; Services \& Advocacy for GLBT Elders, 2014). 
Like other structural barriers such as poverty and insurance inadequacy, barriers based on sexual orientation and identity loom largest when one is most in need of care and comfort, especially during the EOL period (Gorey et al., 2016). In the face of these realities it is imperative for LGBT people to communicate and document their EOL preferences. The ability to proactively make important EOL preparations, including effectively communicating with professional and family caregivers, completing a living will and appointing a health care proxy, are indicative of high quality EOL and palliative care. The aim here is to review what is known about the prevalence of these EOL preparatory behaviors among LGBT people.

Patients typically rely on health care providers to initiate discussions about EOL issues and to provide information about legal options (Hughes \& Cartwright, 2014). Unfortunately, practitioners who do not "specialize" in palliative care often have difficulty timing these discussions. Their concerns with curing disease and prolonging life can cause them to miss EOL discussions even when death is inevitable (Gawande, 2014). Physicians may feel uncomfortable initiating these discussions due to fear of minimizing their patients' sense of hope (Fulton \& Teno, 2014). Consequently, patients may receive unwanted treatments and experience unnecessary transfers between health care facilities, creating added burdens for them and their families (Institute of Medicine, 2014).

Advance directives are intended to promote autonomy by enabling individuals to summarize preferences regarding life-sustaining treatment and to identify their surrogate decision maker in the event that they lose decisional capacity. However, debate exists on the effectiveness of advance directives in general and living wills in particular. Completion of advance directives may not guarantee that the individuals' preferences will be honored. Reasons include that surrogate decision makers may not have reviewed their loved ones' living wills or the preferences outlined in a living will may be too general to address all the medical complexities related to illness. Moreover, the utility of advance directives may be questionable because of the instability of patients' preferences (Fagerlin \& Schneider, 2004). Although the completion of advance directives has increased in the general population, it has had little proven effect on decreasing health care costs (Silveira, Wiitala, \& Piette, 2014). Despite these findings, there is evidence to suggest that persons who have completed advance directives were more likely to receive medical care that was strongly associated with their preferences. Advance directive documents influence the outcomes of decision making at EOL. This supports the continued use of advance directives (Detering, Hancock, Reade, \& Silvester, 2010; Silveira, Kim, \& Langa, 2010).

Much of the research surrounding advance directives has been focused on the completion and utilization of documents and creating a better form. Advance directive documents alone, however, do not improve outcomes; it is only one step in a systemic advance care planning process (Hickman, 
Hammes, Moss, \& Tolle, 2005). The advance care planning process also necessitates discussion between patients and their health care providers (Fulton \& Teno, 2014). Evidence suggests that communication in a coordinated advance care planning process between geriatric patients, families, and health care providers improves patient/family satisfaction with EOL care and reduces the incidence of anxiety, depression, and stress in surviving relatives (Detering et al., 2010). In particular, cancer patients who have engaged in a discussion with their physician about their wishes for EOL care are more likely to receive care that is consistent with their preferences. This improves their chances of experiencing less suffering at the EOL (Mack, Weeks, Wright, Block, \& Prigerson, 2010). A randomized controlled trial of patients with advanced lung cancer who received early integration of palliative care with cancer care found distinct yet complementary differences in their care between palliative care and oncology clinicians in an ambulatory care setting. Although both types of clinicians addressed symptom management and health status, palliative care clinicians focused on the patients' and their family's coping with the progressive illness, developing rapport in the therapeutic alliance, and engaging family members. Discussions about EOL preferences typically occurred as personal needs developed during the course of the disease trajectory rather than at the initial consultation. Thus, complementary teamwork by oncologists and palliative providers facilitates a smoother transition during later stages of illness when more challenging discussions about EOL care are necessary (Yoong et al., 2013).

Regrettably, health care providers tend to mirror society's heteronormative attitudes because they receive so little education and training related to the needs of LGBT people (Buckey \& Browning, 2013; Hughes \& Cartwright, 2014; National Resource Center on LGBT Aging, 2012; Rawlings, 2012). Health care providers' attitudes and consequent systemic discrimination impacts LBGT people's ability to communicate effectively with them. A national poll of LGBT older adults in the United States found that one-third had not disclosed their sexual orientation or identity to their primary health care provider; nearly one-half believe that their relationship would be adversely affected by such disclosure (Services \& Advocacy for GLBT Elders, 2014). Additionally, the LGBT elder's social network of "chosen family members," often not biologically or legally related, are frequently not recognized by providers (Hughes \& Cartwright, 2014; Rawlings, 2012). These communication challenges contribute to vulnerabilities experienced by LGBT community members as they prepare for later life and EOL. Health care providers need to understand the extent of primary caregiver-patient communication problems before effective interventions can be facilitated. The primary purpose of this synthesis is to respond to that need by estimating their prevalence. This objective will be pursued with a rapid integrative review of existing prevalence studies. 
Members of diverse sexual minority groups are often combined as LGBT people in research and advocacy. Clearly, they are not a homogeneous group. Sexual orientation (lesbian, gay, or bisexual) differs from gender identity (transgender, cisgender, or gender non-conforming). Furthermore, there has been limited research on the intersections of any L, G, B, or T populations with other diversities: ethnic/racial, socioeconomic or geographic (Adams, 2016; Institute of Medicine, 2011). There is every reason to believe that they vary widely across a rich continuum of attitudes, beliefs, and behaviors. For example, transgender elders were much more reluctant to discuss their sexuality with their primary care physician than were other sexual minority group members (Services and Advocacy for GLBT Elders, 2014). The need to advance understandings about diversities within and between all LGBT people is glaring. Much of the research in this and related fields has focused on gay men and lesbian women with much less attention paid to bisexual people and almost none to the "invisible T," transgender people (Addis, Davies, Greene, MacBride-Stewart, \& Shepherd, 2009; de Vries et al., 2016; Institute of Medicine, 2011).

One previous systematic review of the needs and preferences for palliative and EOL care among LGBT people narratively explored 12 studies, primarily of cancer care of gay men and lesbian women, published through 2010 (Harding, Epiphaniou, \& Chidgey-Clark, 2012). Essentially, this study crossvalidated the introductory notions about the importance of communication with care providers and clarified the paucity of knowledge on the preparedness of LGBT people for EOL care. However, it had admitted limitations in that it only included peer-reviewed studies and so, could have been confounded by publication bias. Moreover, the review did not identify studies that specifically related the experiences of transgender people. Building on the qualitative, theoretic approach taken by Harding and colleagues, a complementary, quantitative approach is offered herein. It will (1) integrate peer-reviewed published and so-called gray literature-based research that has not been peer-reviewed; (2) target studies of each unique LGBT group, especially transgender people; (3) estimate the prevalence of important EOL preparations among them; and (4) test post-hoc (exploratory) hypotheses about the transgender subgroup's level of preparedness for EOL in comparison to the aggregated LGBT sample.

\section{Methods}

\section{Study procedures}

Rapid review methods were used where streamlined techniques lessened the time required from greater than 12 months to less than 6 months (Ganann, Ciliska, \& Thomas, 2010; Tricco et al., 2015). This rapid review 
was accelerated by the use of a single investigator who searched the following electronic databases from January 1, 2010 to March 1, 2017: LGBT Life, Social Work Abstracts, Social Services Abstracts, Sociological Abstracts, PsycINFO, Cumulative Index of Nursing and Allied Health Literature (CINAHL) Complete, ProQuest Nursing \& Allied Health Database and PubMed. To control for unpublished research, the following electronic databases were searched: ProQuest Dissertations and Theses Global, Web of Science ${ }^{T M}$ Conference Proceeding Citation Indexes-Science and Social Science \& Humanities, and Google Scholar (de Smidt \& Gorey, 1997; Grenier \& Gorey, 1998). Non-peer reviewed publications (e.g., research reports such as http:// www.age-pride.org/wordpress/wp-content/uploads/2011/05/Full-Report-FINAL11-16-11.pdf) were searched via Google Scholar. Search keywords used were (LGBT or lesbian or gay or bisexual or transgender) and (EOL or end-of-life or palliative or hospice or dying or aging). Database searches were augmented in two ways: (1) reference lists of retrieved publications (peer or non-peer reviewed) were examined and (2) authors of retrieved manuscripts were emailed and asked to identify any additional relevant studies whether published, in press, or unpublished. A total of 119 unduplicated, conceptually relevant manuscripts were retrieved.

Studies then had to meet the following empirical criteria: (1) studied at least one of these five formats for EOL preparations - discussed with a primary care giver; discussed with a significant other, family member, friend, or another substitute decision maker; completed a will; completed a living will and/or appointed a health care proxy and (2) findings were reported such that prevalence estimates were calculable. Eight conceptually and empirically relevant surveys were selected for this integrative review. They are noted in the reference section with an asterisk.

\section{Analysis of prevalence estimates}

The outcomes of this integrative review were the prevalence estimates of preparatory behaviors for EOL from the individual studies. A prevalence estimate is the proportion of the sample population who exhibit or have exhibited a certain characteristic - in this instance, completed the preparatory behaviors for EOL by the time of the survey. When a study reported multiple EOL measures or reported those measures for different study subgroups (e.g., LGBT versus transgender people), these were reported as separate measures. The eight surveys each reported up to five types of preparatory EOL behaviors (e.g., completed living will). There were a total of 30 prevalence estimates of the five different behaviors, as not all eight studies examined all five types of preparatory behaviors. (Table 1.) Survey prevalence estimates for each study sample (i.e., LGBT, transgender, and one general population-based comparison group) were abstracted from primary study reports or calculated 
Table 1. Summary of studies on end-of-life care preparations among lesbian, gay, bisexual or transgender people: Behavioral prevalence estimates with 95\% confidence intervals (CI).

\begin{tabular}{|c|c|c|c|c|}
\hline \multirow[b]{2}{*}{ Study Citation } & \multicolumn{2}{|l|}{ Sample } & \multicolumn{2}{|c|}{ Prevalence } \\
\hline & Description of people & Size & Estimate (\%) & $95 \% \mathrm{Cl}$ \\
\hline \multicolumn{5}{|c|}{ Discussed end-of-life preferences with primary care provider } \\
\hline MetLife Mature Market Institute, 2010 & LGBT & 1201 & 10.0 & $8.4,11.8$ \\
\hline Hughes \& Cartwright, 2014 & LGBT & 300 & 12.7 & $9.4,16.9$ \\
\hline \multicolumn{5}{|c|}{ Discussed end-of-life preferences with significant other } \\
\hline MetLife Mature Market Institute, $2010^{\circ}$ & LGBT & 1201 & 45.0 & $42.2,47.8$ \\
\hline Hughes \& Cartwright, 2015 & LGBT & 286 & 52.1 & $46.3,57.8$ \\
\hline de Vries et al., 2016 & LGBT & 92 & 68.5 & $58.4,77.1$ \\
\hline de Vries et al., 2016 & Transgender & 23 & 65.2 & $44.9,81.2$ \\
\hline \multicolumn{5}{|l|}{ Completed will } \\
\hline Fredriksen-Goldsen et al., 2011 & LGBT & 2560 & 70.0 & $68.2,71.7$ \\
\hline MetLife Mature Market Institute, 2010 & LGBT & 1201 & 37.0 & $34.3,39.7$ \\
\hline de Vries et al., 2016 & LGBT & 92 & 67.4 & $57.3,76.1$ \\
\hline de Vries et al., 2016 & Transgender & 23 & 65.2 & $44.9,81.2$ \\
\hline Witten, 2014 & Transgender & 1963 & 14.1 & $12.6,15.7$ \\
\hline Witten, 2015 & Transgender lesbian & 276 & 47.8 & $42.0,53.7$ \\
\hline Fredriksen-Goldsen et al., 2011 & Transgender & 174 & 48.9 & $41.5,56.0$ \\
\hline Witten, 2016 & Transgender bisexual & 147 & 27.9 & $21.3,35.6$ \\
\hline \multicolumn{5}{|l|}{ Completed living will } \\
\hline MetLife Mature Market Institute, 2010 & LGBT & 1201 & 38.0 & $35.3,40.8$ \\
\hline Hughes \& Cartwright, 2015 & LGBT & 285 & 12.3 & $9.0,16.6$ \\
\hline de Vries et al., 2016 & LGBT & 92 & 46.7 & $36.9,56.9$ \\
\hline de Vries et al., 2016 & Transgender & 23 & 39.1 & $22.2,59.2$ \\
\hline Witten, 2014 & Transgender & 1963 & 13.1 & $11.7,14.7$ \\
\hline Witten, 2015 & Transgender lesbian & 276 & 39.9 & $34.3,45.7$ \\
\hline Witten, 2016 & Transgender bisexual & 147 & 22.4 & $16.5,29.9$ \\
\hline \multicolumn{5}{|l|}{ Appointed a health care proxy } \\
\hline Fredriksen-Goldsen et al., 2011 & LGBT & 2560 & 64.0 & $62.1,65.8$ \\
\hline MetLife Mature Market Institute, 2010 & LGBT & 1201 & 34.0 & $31.4,36.7$ \\
\hline Hughes \& Cartwright, 2015 & LGBT & 285 & 18.2 & $14.2,23.1$ \\
\hline de Vries et al., 2016 & LGBT & 92 & 52.2 & $42.1,62.1$ \\
\hline de Vries et al., 2016 & Transgender & 23 & 47.8 & $29.2,67.0$ \\
\hline Witten, 2014 & Transgender & 1963 & 10.7 & $9.4,12.2$ \\
\hline Witten, 2015 & Transgender lesbian & 276 & 38.0 & $32.5,43.9$ \\
\hline Fredriksen-Goldsen et al., 2011 & Transgender & 174 & 36.8 & $30.0,44.2$ \\
\hline Witten, 2016 & Transgender bisexual & 147 & 15.6 & $10.7,22.4$ \\
\hline
\end{tabular}

from reported frequencies and sample sizes. Prevalence estimates were determined for each reported outcome and reported as percentages along with their normal or asymptotic 95\% confidence intervals (CI) (Fleiss, Levin, \& Paik, 2003).

As the prevalence estimates were all discrete, those from similar studies were pooled for relevant between-group comparisons. This is the most desirable method of combining the findings of independent studies allowing for the most powerful overall estimates (Cooper, 2017; Cooper \& Patall, 2009). Analyses were primarily descriptive, albeit, quantitative. Medians, rather than means, were reported in describing study outcomes within EOL measures, as the median is much less affected by atypical outliers. The practical significance of all between-group comparisons were assessed with pooled prevalence ratios 
(PR) and 95\% CIs derived from $\chi^{2}$ tests (Fleiss et al., 2003). A 95\% CI that does not include the null value of 1.00 indicates that the difference between the two groups was statistically significant $(p<0.05)$. A PR is simply the ratio of one group's prevalence estimate to another's. For example, a PR of 0.50 comparing the prevalence of having a living will among transgender people $(15.0 \%)$ with that of other sexual minority group members $(30.0 \%)$ would be interpreted as follows: transgender people were one-half as likely to have a living will. PRs less than 1.00 indicate a disadvantage and greater than 1.00, an advantage. Aggregating samples across categorically similar studies, prevalence estimates were compared across these and other groups of interest. For example, the possibility of publication bias by statistically and practically comparing the pooled findings of published and unpublished studies was explored. Similar to weighting effects in meta-analysis, such aggregations of study samples ensured that larger, more precise, studies would influence each synthesis more than smaller studies (Cooper, 2017).

There were three post-hoc (exploratory) hypotheses tested on the behaviors of having completed a will, a living will, or a health care proxy. Examined were whether transgender people might have been less prepared for EOL than the aggregated group of LGBT members. The pooled between-group differences on these three discrete outcomes were tested with chi-square $\left(\chi^{2}\right)$ statistics at an $\alpha$-level of 0.05 . As these were post-hoc examinations, no power estimate was calculated.

\section{Results}

\section{Sample description}

Surveys of 6,116 LGBT people, in aggregate, were accomplished in the United States (2 studies), Canada (1 study), and Australia (2 studies), and three international surveys were predominantly North American. All but one of the studies used online survey methods, typically augmented by multi-method community agency-based recruitment. The other used focus groups to incrementally build its survey sample. Five studies sampled older adults 40-60 years of age or older while three sampled all adults 18 years of age and older. In aggregate, more than $90 \%$ of the aggregated LGBT sample was comprised of gay men or lesbian women. There were three studies of transgender people: one was exclusively transgender, a second consisted of transgender lesbians, and the third of transgender bisexuals. From the two studies that reported various socioeconomic details, high status was inferred from the following: " $75 \%$ to $90 \%$ had achieved a college degree or higher" or "incomes were above the norm." Also, more than $90 \%$ of the aggregate sample was non-Hispanic white people, approximately one-half of whom were partnered or married. Five of the studies were reported in peer-reviewed journals 
(Hughes \& Cartwright, 2014; Hughes \& Cartwright, 2015; Witten, 2014; Witten, 2015; Witten, 2016) while two others were nonpeer-reviewed publications (Fredriksen-Goldsen et al., 2011; MetLife Mature Market Institute, 2010) and one was presented as a webinar (de Vries et al., 2016).

\section{Prevalence of EOL preparations}

The eight surveys' 30 independent prevalence estimates are displayed in Table 1. First, the findings of two studies displayed in the top of the table converged to strongly suggest that very few LGBT people, perhaps only one in every ten, engage in EOL discussions with their primary health care providers (10\% to $13 \%)$. Moreover, among those who did discuss EOL preferences with their providers, nearly all (92\%) raised the issue themselves (Hughes \& Cartwright, 2014). Moving down the table, there appears to be evidence of protective factors related to being a member of the LGBT community. These strengths and resiliencies were suggested by the findings that the majority of LGBT people surveyed had discussed their EOL preferences with significant others, family members, friends or substitute decision makers (45-69\%, median $=52 \%)$ and about two-thirds of them had completed a will $(37-70 \%$, median $=67 \%)$. A smaller portion of LGBT people, however, had completed a living will $(12-47 \%$, median $=38 \%)$ or appointed a heath care proxy $(18-64 \%$, median $=43 \%)$.

As an addendum, because comparisons with sexual majority people were not central to this study's purpose, the findings of one U.S. study that compared LGBT people with people from the general population, presumably most of whom were straight, was secondarily analyzed (MetLife Mature Market Institute, 2010; see Table 2). The findings are again consistent with the notion of relative strengths and resiliencies in the LGBT community. LGBT respondents were two and a half times more likely than general population respondents to have engaged in EOL discussions with primary care providers $(\mathrm{PR}=2.50,95 \% \mathrm{CI} 1.83,3.41)$. LGBT participants were also substantially and significantly more likely to have completed a living will $(\mathrm{PR}=1.36,95 \% \mathrm{CI} 1.21,1.53)$ and a power of attorney for health care $(\mathrm{PR}=1.79,95 \%$ CI $1.56,2.06)$.

\section{Transgender subgroup}

One study had a remarkably large sample of 1,963 transgender people (Witten, 2014). This sample allowed for rather precise estimation that transgender people have the lowest prevalence of completed legal documentation related to EOL options: only $14 \%$ completed a will, $13 \%$ completed a living will and $11 \%$ assigned a health care proxy. Aggregating it with the other transgender samples and comparing with the aggregated LGBT samples consistently found transgender disadvantages. They were much less likely to have 
Table 2. Comparisons of end-of-life preparations among lesbian, gay, bisexual and transgender people and people in the general population.

\begin{tabular}{|c|c|c|c|c|}
\hline \multicolumn{2}{|l|}{ Sample } & \multirow{2}{*}{$\frac{\text { Prevalence }}{\text { Estimates (\%) }}$} & \multirow{2}{*}{$\frac{\text { Prevalence }}{\text { Ratio }^{a}}$} & \multirow{2}{*}{$\frac{95 \%}{\text { Confidence Interval }}$} \\
\hline Description of people & Size & & & \\
\hline \multicolumn{5}{|c|}{ Discussed end-of-life preferences with primary care provider } \\
\hline General population & 1206 & 4.0 & 1.00 & \\
\hline LGBT & 1201 & 10.0 & 2.50 & $1.83,3.41$ \\
\hline \multicolumn{5}{|c|}{ Discussed end-of-life preferences with significant other } \\
\hline General population & 1206 & 48.0 & 1.00 & \\
\hline LGBT & 1201 & 45.0 & 0.94 & $0.87,1.02$ \\
\hline \multicolumn{5}{|l|}{ Completed will } \\
\hline General population & 1206 & 39.0 & 1.00 & \\
\hline LGBT & 1201 & 37.0 & 0.95 & $0.86,1.05$ \\
\hline \multicolumn{5}{|l|}{ Completed living will } \\
\hline General population & 1206 & 28.0 & 1.00 & \\
\hline LGBT & 1201 & 38.0 & 1.36 & $1.21,1.53$ \\
\hline \multicolumn{5}{|c|}{ Appointed a health care proxy } \\
\hline General population & 1206 & 19.0 & 1.00 & \\
\hline LGBT & 1201 & 34.0 & 1.79 & $1.56,2.06$ \\
\hline
\end{tabular}

Note. Bolded prevalence ratios are statistically significant; $\chi^{2}$ test $p<0.05$.

${ }^{\mathrm{a} A}$ prevalence ratio of 1.00 is the baseline.

completed a will: $21.3 \%$ versus $59.6 \%, \chi^{2}(1, N=6,436)=921.83, p<0.05$, $\mathrm{PR}=0.36$ (95\% CI $0.39,0.41)$. The transgender participants were approximately one-half as likely to have completed a living will: $17.0 \%$ versus $33.8 \%, \chi^{2}(1, N=3,987)=148.29, p<0.05, \mathrm{PR}=0.50$ (95\% CI 0.45, 0.56). They were much less likely to have appointed a health care proxy: $16.0 \%$ versus $51.9 \%, \chi^{2}(1, N=6,721)=870.00, p<0.05, \mathrm{PR}=0.31(95 \%$ CI $0.29,0.34)$.

\section{Published versus unpublished research}

For the first three displayed outcomes in Table 1, published and unpublished studies cross-validated each other because their aggregated findings did not differ substantively or significantly. However, aggregated study findings did differ by publication status for the next two. Restricting the analysis to LGBT samples for the sake of analytic power and to control LGBT-transgender confounding, pooled estimates of unpublished studies were larger than their published prevalence rates: completed a living will, 38.6\% (de Vries et al., 2016; MetLife Mature Market Institute, 2010) versus $12.3 \%, \chi^{2}(1, N=$ $1,578)=72.21, p<0.05 ; \mathrm{PR}=3.14$ (95\% CI 2.41, 4.09); and appointed a health care proxy, 54.4\% (de Vries et al., 2016; Fredriksen-Goldsen et al., 2011; MetLife Mature Market Institute, 2010) versus 18.2\%, $\chi^{2}(1, N=4,138)=$ 138.95, $p<0.05 ; \mathrm{PR}=2.99$ (95\% CI 2.48, 3.60). The differences between unpublished and published study findings, however, did not seem to potently confound the post-hoc hypotheses on transgender disadvantage. For example, they were estimated to be somewhat less likely to have appointed a health care proxy based on either unpublished $[38.1 \%$ (de Vries et al., 2016; Fredriksen-Goldsen et al., 2011) versus 54.4\%, 
$\chi^{2}(1, N=4,050)=20.09, p<0.05, \mathrm{PR}=0.70(95 \%$ CI $\left.0.60,0.82)\right]$ or published research $[14.2 \%$ (Witten, $2014 ; 2015 ; 2016)$ versus $18.2 \%, \chi^{2}(1, N=2,671)=$ 3.32, $p=0.07, \mathrm{PR}=0.78$ (90\% CI 0.62, 0.98)].

\section{Discussion}

Many LGBT adults have completed advanced directives and have discussed their EOL preferences with their significant other. Like many others in North America, however, it seems that the vast majority of LGBT people in their middle to later years have never talked about EOL care with their primary health care provider. Previous studies revealed that a coordinated advance care planning approach between patients and health care providers lead to improved outcomes (Detering et al., 2010; Mack et al, 2010). Thus, LGBT people's lack of advance care planning with a health care professional could leave them particularly vulnerable to not having their preferences be respected during their EOL journey. This finding, which was consistently evident across the research reviewed for this study, is particularly disconcerting, as it seemed to validate a concern about the lack of comfort among health care providers in raising EOL issues and advance care planning with all their patients. This is especially important for LGBT individuals. Lack of provider knowledge about the LGBT population perpetuates the discrimination experienced by LGBT people, and is a systemic barrier which prevents them from accessing quality health care.

Moreover, the potential adverse impact of the lack of advance care planning is underscored by the marked health disparities experienced by the LGBT population, particularly as some of these disparities have mortality implications. These health disparities are often the results of marginalization, economic problems, and internalized stigma. The common causative factor in these health risks is not inherent in the sexual orientation or gender identity of these individuals. Rather, it is in "living as a LGBT person in a homophobic society" (Kelley, Chou, Dibble, \& Robertson, 2008, p. 252). For example, many LGBT persons are less likely to have employer-based health insurance which can lead to unmet health needs, poor health outcomes, or earlier onset of chronic conditions (Farmer \& Yancu, 2015). Evidence suggests that LBG older adults report higher levels of poor general health, disability, and depression which is influenced by their internalized stigma (Fredriksen-Goldsen et al., 2013a). When compared with heterosexual older adults, LGB older adults have poorer mental health (Fredriksen-Goldsen, Kim, Barkan, Muraco, \& Hoy-Ellis, 2013b). LGBT older adults are also at higher risk of smoking, excessive drinking, and non-prescribed drug use (Fredriksen-Goldsen et al., 2011). These health disparities affect LGBT patients' quality of life and impact their EOL journey. 
This rapid review's evidence underscored apparent strengths and resiliencies among its aggregate LGBT participants and their significant others. On certain important elements of EOL care preparation such as communication with each other and legal documentations, LGBT people seemed to have done as well or much better than their heterosexual counterparts. This may have been a response to not having a national, legally-recognized marital status and was their way of coping with systemic discrimination. Much of the survey data reviewed was originally collected before same-sex marriage became legalized in the United States. Prior to the U.S. Supreme Court's decision to legalize same sex marriage on June 26, 2015, same sex couples were not granted the same rights as heterosexual couples. Despite years of domestic partnership, same sex couples were not afforded the same default decision maker status as heterosexual married couples. LGBT individuals faced a significant risk that someone other than their life partner would make medical decisions for them if they become incapacitated and that these decisions may conflict with their preferences. Within such a hostile legal and social environment, LGBT people may simply have had to keep their affairs in order out of necessity, and to support each other through important extended family networks which transcend biological or legal ties. Thus, the completion of advance directives for same sex couples was critical for safeguarding the legal authority of a chosen loved one to participate in medical decision making (Blevins \& Werth, 2006; Wahlert \& Fiester, 2013).

Regrettably, consistent and strong support for the hypothesis that transgender people are less prepared for EOL than LGB members was found. They were $50-70 \%$ less likely than other sexual minority group members to have a will, a living will or to have appointed a health care proxy. Therefore, transgender people seem largely disadvantaged, ill prepared for EOL, and thus, much less likely to receive high quality EOL care than other sexual minority or general population members.

\section{Limitations}

Much of what has been learned about LGBT people's experiences, including their preparation for EOL, has been through the use of online surveys. They were central to the multi-method sampling frames used in seven of the eight studies which were reviewed. In fact, researchers likely could not have gathered such evidence from national and international surveys, some of which were quite large, without the use of online methods. In this instance, their central strength is that they can bolster participation among those who, with good reason, may fear discrimination (Wright, 2005). They do, however, have some limitations. Because investigators do not know the size of their study's accessible population (i.e., how many eligible study participants are actually "out there" in cyberspace), they are unable to calculate 
a response rate. Consequently, it can be difficult for them to assess with certainty how various sources of bias may affect their study's internal and external validity. For the following reasons, the likely direction of any such bias is clear in this instance. First, most of the participants in the studies which were reviewed had to have had access to a computer and internet service, suggesting that they probably did not live in poverty. Second, many were probably well-connected in their communities as most of the sampling also used agency-augmented methods. Third, the samples described were consistently of very high socioeconomic status. Fourth, such social and economic means are likely associated with inclinations and abilities to discuss EOL care with professionals and to prepare requisite legal documents. Therefore, any injected bias into the analyses of these primarily online surveys likely render them to be underestimates of the population parameters. Thus, any identified problems (e.g., only 1 of 10 LGBT people discussed EOL care with a primary care provider) are probably worse than estimated.

Another potential limitation of this review involves possible confounding of the transgender analysis by age. The three exclusive studies of transgender people were also the three studies of entire adult cohorts. In addition to middle-aged and older adults they also included younger adults between 18 and 40 years of age. Therefore, it is possible that the estimations of less prevalent EOL preparations among transgender people were not, in fact, an effect of their sexual identities but rather, a cohort effect-that is, a younger cohort being less concerned with EOL issues. This did not fatally-confound the analysis, as two other study subsamples of older transgender cohorts, 40-50 years of age or older, were also utilized in the analysis. The primary studies did not account for age in their analyses so this variable could not be considered. In addition to the lack of socioeconomic diversity, there was a lack of ethnic and racial diversity as this review was primarily comprised of non-Hispanic white people. Given the well-known ethnic/racial inequities in American health care and likely in EOL care as well, intersectional arguments to advance knowledge about more ethnically and racially diverse LGBT people are clear (Addis et al., 2009; Bowleg, 2012).

\section{Future research needs}

Issues that are important to the LGBT population have been neglected by public health research. LGBT persons are underrepresented in research studies (Boehmer, 2002). This makes it difficult to characterize the general health or well-being of the LGBT community. The lack of a census count precludes even an accurate understanding of the size of this population in the U.S. (Blevins \& Werth, 2006; Choi \& Meyer, 2016). Recent reversals by the Executive Branch in 2017 to collect data on national surveys regarding sexual orientation and gender identity will further hamper understanding of 
issues important to the LGBT community (Cahill \& Makadon, 2017). Much of what is known about the challenges experienced by this population is derived from community-based, non-probability studies (Choi \& Meyer, 2016).

Notwithstanding the relative ease and access of online surveys, a welldesigned and amply funded offline survey would go a long way toward either affirming or refuting this field's extant synthetic knowledge. Perhaps sampling frames of large, statewide or regional health care providers could be used. Furthermore, such surveys of both LGBT persons and their providers would help us to better understand their interactions. In addition, longitudinal studies would help us to understand better how to provide the highest quality of care over the life course and within the continuum from primary and specialized care to EOL care. As primary data is developed and secondary data analyzed and synthesized, understanding the unique experiences of diverse transgender and bisexual people as well as lesbian women and gay men is important. To the extent that it is possible within each practice-research context, this future research agenda ought to fully describe and analyze how other intersecting characteristics like age, gender, ethnicity, and race also matter (or not) among all people-LGBT, heterosexual, and cisgender.

Prevalence studies in this field have effectively framed the problem. Notwithstanding their suggested strengths and resiliencies, LGBT people in general and perhaps transgender people especially, appear not well prepared for and not well supported in EOL care. What about solutions? What is known about the lived experiences of LGBT people during their EOL journeys? It appears very little. Qualitative research giving voice to the rich narratives of LGBT people (and health care providers) could be most helpful in developing ideas about how to better serve and ultimately intervene to ensure more accessible and effective EOL care. Intensive qualitative studies with small groups of transgender people, for example, could help us to better understand not merely their vulnerabilities and experiences of barriers, but also the unique strengths and resiliencies that they, their partners, families, and communities possess. This knowledge could most assuredly be instrumental in the development and provision of more culturally competent EOL care, including palliative care, to all of the diverse members of this presently marginalized population.

\section{Implications for practice}

Healthcare practitioners need to increase their comfort in initiating and engaging in EOL discussions with their patients. Death and dying do not have to be taboo subjects. Conversations about death and dying can be normalized. These conversations can focus on the well-being of the whole person and not only on curative treatments to prolong life. Hospitalizations and healthcare 
costs can be reduced and quality of life can improve (Gawande, 2014; Institute of Medicine, 2014). In addition, healthcare providers are responsible for knowing about laws pertaining to EOL options in their country and the legal documents which patients may complete to specify their preferences. Patients may not be aware of their options and rely on healthcare practitioners to provide this information (Hughes \& Cartwright, 2014; Institute of Medicine, 2014).

Health care providers are responsible for removing barriers by creating a welcoming, nonjudgmental, and inclusive environment for their patients. If health care providers demonstrate respect for sexual and gender diversity, LGBT clients will feel safer to seek medical care and to be open about their preferences. Awareness about people's sexuality or gender identity is a necessary component to providing holistic, patient-centered care (Harding, Epiphaniou, \& Chidgey-Clark, 2012). To serve the LGBT community more effectively, practitioners should acknowledge the nontraditional family structures and expand their definition of family to be more inclusive of LGBT caregiving resources (National Resource Center on LGBT Aging, 2012; MetLife Mature Market Institute, 2010). Respecting people's preferences includes involving their partners in the decision-making process regarding medical treatment (Harding, Epiphaniou, \& Chidgey-Clark, 2012), using gender neutral language when asking patients about their partner or social support system, and providing statements reflecting equality for everyone (Buckey \& Browning, 2013). "Service providers must commit to educating themselves on the needs of the LGBT population" (Buckey \& Browning, 2013, p. 246)

\section{Conclusion}

This integrative review found some evidence of EOL preparatory behaviors with family members of choice by LGBT people. Few, however, seemed to have ever discussed EOL issues with their primary health care provider. Furthermore, transgender people appear to be the least prepared for EOL and therefore, at greatest risk of experiencing substandard EOL care. There does not yet seem to be evidence for confident policy decisions to substantially ameliorate the problem. Heteronormative and death communication avoidance among health care providers are pernicious barriers to delivering high quality care. Therefore, pending the next generation of needed mixmethods research, large consciousness raising efforts-including the advancements of LGBT cultural competencies-seem called for in the interim. Curricula to educate and train allied health care professions, including physicians, nurses, and social workers, is needed to promote cultural sensitivity in working with LGBT people and their families during the EOL journey. 


\section{Acknowledgments}

Gratitude is expressed for the library science support of Sharon Munro, Information Services Librarian, Leddy Library, University of Windsor and also for the collegial assistance of Faith Hopp, Associate Professor, School of Social Work, Wayne State University who provided insightful internal review of this manuscript.

\section{Funding}

This study was supported in part by an Ontario Graduate Scholarship.

\section{ORCID}

Luisa Kcomt (D) http://orcid.org/0000-0001-5815-0966

Kevin M. Gorey (D) http://orcid.org/0000-0003-1870-6549

\section{References}

References marked with an asterisk indicate studies included in the integrative review.

Adams, M. (2016). An intersectional approach to services and care for LGBT elders. Journal of the American Society on Aging, 40(2), 94-100.

Addis, S., Davies, M., Greene, G., MacBride-Stewart, S., \& Shepherd, M. (2009). The health, social care and housing needs of lesbian, gay, bisexual, and transgender older people: A review of the literature. Health and Social Care in the Community, 17(6), 647-658. doi:10.1111/j.1365-2524.2009.00866.x

Blevins, D. \& Werth Jr., J. L. (2006). End-of-life issues for LGBT older adults. In D. Kimmel, T. Rose, \& S. David (Eds.), Lesbian Gay, Bisexual, and Transgender Aging: Research and Clinical Perspectives (pp. 206-226). New York, U.S.: Columbia University Press.

Boehmer, U. (2002). Twenty years of public health research: Inclusion of lesbian, gay, bisexual, and transgender populations. American Journal of Public Health, 92(7), 1125-1130. doi:10.2105/AJPH.92.7.1125

Bowleg, L. (2012). The problem with the phrase women and minorities: Intersectionality-an important theoretical framework for public health. American Journal of Public Health, 102(7), 1267-1273. doi:10.2105/AJPH.2012.300750

Buckey, J. W., \& Browning, C. N. (2013). Factors affecting the LGBT population when choosing a surrogate decision maker. Journal of Social Service Research, 39(2), 233-252. doi:10.1080/01488376.2012.754205

Cahill, S. R. \& Makadon, H. J. (2017). If they don't count us, we don't count: Trump administration rolls back sexual orientation and gender identity data collection. LGBT Health, 4(3), 1-3. doi:10.1089/lgbt.2017.0073

Choi, S. K. \& Meyer, I. H. (2016). LGBT Aging: A Review of Research Findings, Needs, and Policy Implications. Los Angeles: The Williams Institute. Retrieved from https://williams institute.law.ucla.edu/wp-content/uploads/LGBT-Aging-A-Review.pdf

Cooper, H. (2017). Research synthesis and meta-analysis: A step-by-step approach (5th ed.). Thousand Oaks, CA: Sage.

Cooper, H., \& Patall, E. A. (2009). The relative benefits of meta-analysis using individual participant data and aggregate data. Psychological Method, 14(2), 165-176. doi:10.1037/ a0015565 
Detering, K. M., Hancock, A. D., Reade, M. C., \& Silvester, W. (2010). The impact of advance care planning on end of life care in elderly patients: Randomised controlled trial. BMJ, 340, 1345. doi:10.1136/bmj.c1345.

de Smidt, G. A., \& Gorey, K. M. (1997). Unpublished social work research: Systematic replication of a recent meta-analysis of published intervention effectiveness research. Social Work Research, 21(1), 58-62. doi:10.1093/swr/21.1.58

*de Vries, B., Gutman, G., Chamberland, L., Fast, J., Gahagan, J., Mock, S., \& Humble, A. (2016). Enhancing end-of-life discussions and planning among LGBT older Canadians [Webinar]. In Canadian frailty network webinar series. Retrieved from http://www.cfnnce.ca/news-and-events-overview/webinars/fostering-end-of-life-conversations,-care-andcommunity-among-lgbt-older-canadians/

Fagerlin, A. \& Schneider, C. E. (2004). Enough: The failure of the living will. Hastings Center Report, 34(2), 30-42. doi:10.2307/3527683

Farmer, D. F. \& Yancu, C. N. (2015). Hospice and palliative care for older lesbian, gay, bisexual, and transgender adults: The effect of history, discrimination, health disparities and legal issues on addressing service needs. Palliative Medicine and Hospice Care, 1(2), 36-43. doi:10.17140/PMHCOJ-1-107

Fleiss, J. L., Levin, B., \& Paik, M. C. (2003). Statistical methods for rates and proportions (3rd ed.). New York, NY: John Wiley \& Sons. doi:10.1002/0471445428

Fredriksen-Goldsen, K. I., Emlet, C. A., Kim, H., Muraco, A., Erosheva, E. A., Goldsen, J., \& Hoy-Ellis, C. P. (2013a). The physical and mental health of lesbian, gay male, and bisexual (LGB) older adults: The role of key health indicators and risk and protective factors. The Gerontologist, 53(4), 664-675. doi:10.1093/geront/gns123

Fredriksen-Goldsen, K. I., Kim, H-J., Barkan, S. E., Muraco, A., Hoy-Ellis, C. P. (2013b). Health disparities among lesbian, gay, and bisexual older adults: Results from a population-based study. American Journal of Public Health, 103(10), 1802-1809. doi:10.2105/ AJPH.2012.301110

${ }^{*}$ Fredriksen-Goldsen, K. I., Kim, H.-J., Emlet, C. A., Muraco, A., Erosheva, E. A., Hoy-Ellis, C. P., ... Petry, H. (2011). The aging and health report: Disparities and resilience among lesbian, gay, bisexual, and transgender older adults. Seattle: Institute for Multigenerational Health. Retrieved from http://caringandaging.org/wordpress/wp-content/uploads/ 2011/05/Full-Report-FINAL-11-16-11.pdf

Fulton, A. T. \& Teno, J. M. (2014). Advance care planning: Focus on communication and care planning rather than on building the perfect form. In L. Rogne \& S. McCune (Eds.), Advance care planning: Communicating about matters of life and death (pp. 33-44). New York, NY: Springer Publishing Company.

Ganann, R., Ciliska, D., \& Thomas, H. (2010). Expediting systematic reviews: Methods and implications of rapid reviews. Implementation Science, 5, 56. doi:10.1186/1748-5908-5-56

Gawande, A. (2014). Being mortal: Medicine and what matters in the end. New York: Metropolitan Books.

Gorey, K. M., Bartfay, E., Kanjeekal, S. M., Wright, F. C., Hamm, C., Luginaah, I. N., ... Balagurusamy M. K. (2016). Palliative chemotherapy among people living in poverty with metastasised colon cancer: Facilitation by primary care and health insurance. BMJ Supportive \& Palliative Care. Advance online publication. doi:10.1136/bmjspcare-2015-001035

Grenier, A. M., \& Gorey, K. M. (1998). Effectiveness of social work with older people and their families: A meta-analysis of conference proceedings. Social Work Research, 22(1), 60-64. doi:10.1093/swr/22.1.60

Harding, R., Epiphaniou, E., \& Chidgey-Clark, J. (2012). Needs, experiences, and preferences of sexual minorities for end-of-life care and palliative care: A systemic review. Journal of Palliative Medicine, 15(5), 602-611. doi:10.1089/jpm.2011.0279 
Hickman, S. E., Hammes, B. J., Moss, A. H., \& Tolle, S. W. (2005). Hope for the future: Achieving the original intent of advance directives. Improving End of Life Care: Why Has It Been So Difficult? Hastings Center Report Special Report, 35(6), S26-S30.

${ }^{*}$ Hughes, M., \& Cartwright, C. (2014). LGBT people's knowledge of and preparedness to discuss end-of-life care planning options. Health and Social Care in the Community, 22(5), 545-552. doi:10.1111/hsc. 12113

${ }^{\star}$ Hughes, M. \& Cartwright, C. (2015). Lesbian, gay, bisexual and transgender people's attitudes to end-of-life decision-making and advance care planning. Australasian Journal on Ageing, 34(S2), 39-43. doi:10.1111/ajag.12268

Institute of Medicine. (2011). The health of lesbian, gay, bisexual, and transgender people: Building a foundation for better understanding. Retrieved from https://iom.nationalacademies.org/Reports/2011/The-Health-of-Lesbian-Gay-Bisexual-and-Transgender-People.aspx

Institute of Medicine. (2014). Dying in America: Improving quality and honoring individual preferences near the end of life. Washington, DC: Institute of Medicine. Retrieved from http://www.nationalacademies.org/hmd/ /media/Files/Report\%20Files/2014/EOL/Report\% 20Brief.pdf

Kelley, L., Chou, C. L., Dibble, S. L., \& Robertson, P. A. (2008) A critical intervention in lesbian, gay, bisexual, and transgender health: Knowledge and attitude outcomes among second-year medical students. Teaching and Learning in Medicine, 20(3), 248-253, doi:10.1080/10401330802199567

Mack, J. W., Weeks, J. C., Wright, A. A., Block, S. D., \& Prigerson, H. G. (2010). End-of-life discussions, goal attainment, and distress at the end of life: Predictors and outcomes of receipt of care consistent with preferences. Journal of Clinical Oncology, 28(7), 1203-1208. doi:10.1200/JCO.2009.25.4672

*MetLife Mature Market Institute. (2010). Still out, still aging: The MetLife study of lesbian, gay, bisexual, and transgender baby boomers. New York: MetLife Mature Market Institute. Retrieved from https://www.metlife.com/assets/cao/mmi/publications/studies/2010/mmistill-out-still-aging.pdf

National Resource Center on LGBT Aging (2012). Inclusive services for LGBT older adults: A practical guide to creating welcoming agencies. Retrieved from http://www.lgbtaging center.org/resources/resource.cfm? $\mathrm{r}=487$

Rawlings, D. (2012). End-of-life care considerations for gay, lesbian, bisexual, and transgender individuals. International Journal of Palliative Nursing, 18(1), 29-34. doi:10.12968/ ijpn.2012.18.1.29

Services and Advocacy for GLBT Elders. (2014). Out and visible: The experiences and attitudes of lesbian, gay, bisexual and transgender older adults, ages 45-75. Retrieved from http:// www.sageusa.org/resources/publications.cfm

Silveira, M. J., Kim, S. Y. H., \& Langa, K. M. (2010). Advance directives and outcomes of surrogate decision making before death. The New England Journal of Medicine, 362(13), 1211-1218. doi:10.1056/NEJMsa0907901

Silveira, M. J., Wiitala, W., \& Piette, J. (2014). Advance directive completion by elderly Americans: A decade of change. Journal of the American Geriatric Society, 62(4), 706-710. doi:10.1111/jgs.12736

Tricco, A. C., Antony, J., Zarin, W., Strifler, L., Ghassemi, M., Ivory, J., Perrier, L., Hutton, B., Moher, D., \& Straus, S. E. (2015). A scoping review of rapid review methods. BMC Medicine, 13, 224. doi:10.1186/s12916-015-0465-6

Wahlert, L. \& Fiester, A. (2013). A false sense of security: Lesbian, gay, bisexual, and transgender (LGBT) surrogate health care decision-making rights. Journal of the American Board of Family Medicine, 26(6), 802-804. doi:10.3122/jabfm.2013.06. 130130 
*Witten, T. M. (2014). End of life, chronic illness, and trans-identities. Journal of Social Work in End-of-Life \& Palliative Care, 10(1), 34-58. doi:10.1080/15524256.2013.877864

${ }^{*}$ Witten, T. M. (2015). Elder transgender lesbians: Exploring the intersection of age, lesbian sexual identity, and transgender identity. Journal of Lesbian Studies, 19(1), 73-89. doi:10.1080/10894160.2015.959876

${ }^{\star}$ Witten, T. M. (2016). Aging and transgender bisexuals: Exploring the intersection of age, bisexual sexual identity, and transgender identity. Journal of Bisexuality, 16(1), 58-80. doi:10.1080/15299716.2015.1025939

Wright, K. B. (2005). Researching internet-based populations: Advantages and disadvantages of online survey research, online questionnaire authoring software packages, and web survey services. Journal of Computer-Mediated Communication, 10, 3. doi:10.1111/j.10836101.2005.tb00259.x

Yoong, J., Park, E. R., Greer, J. A., Jackson, V. A., Gallagher, E. R., Pirl, W. F., ... Temel, J. S. (2013). Early palliative care in advanced lung cancer. Journal of American Medical Association, 173(4), 283-290. doi:10.1001/jamainternmed.2013.1874 